\title{
A DECISION SUPPORT SYSTEM FOR BIDDING PROCESS
}

\author{
Ascensión Zafra-Cabeza, Miguel A. Ridao, Eduardo F. Camacho \\ Departamento de Ingenieria de Sistemas y Automática, Universidad de Sevilla, Camino de los Descubrimientos \\ $s / n, 41092$, Sevilla, SPAIN
}

\begin{abstract}
This article has been developed in the frame of an IST European Project, where Companies and Universities of several countries of Europe have collaborated. The work presents a Decision Support System (DSS) to provide help in the bidding process. Critical decisions as bid/no bid, make/buy or decision of best final proposal have been realised. The tool performs a risk analysis and it uses the results in all the DSS phases. Copyright (C) 2002 IFAC
\end{abstract}

Keywords: Decision Support Systems, Risk, Management Systems, Knowledge engineering, Business engineering.

\section{INTRODUCTION}

Decision Support Systems comprise a large body of research and it remains an active area of investigation (Keen and Scott-Morton, 1978; Thierauf, 1982; Sprague, 1993; Druzdzel and Flynn, 1999; Gray, 1994; Simon, 1960). A Definition about the DSS has been taken from E. Turbam, (Turbam, 1988). "A DSS is an interactive, flexible, and adaptable Computerbased information systems (CBIS) that utilizes decision rules, models, and model base coupled with a comprehensive database and the decision maker's own insights, leading to specific, implementable decisions in solving problems that would not be amenable to management science optimization models per se. Thus, a DSS supports complex decision making and increases its effectiveness".

Aiding the deficiencies of human judgement and decision making has been a major focus of science through its history, because in many situations the quality of decisions is important, as particularly in complex systems, as management of organizational operations, industrial processes, or bidding processes (Seydel and Olson, 2001). It is in this last field where our research has been developed.

There is a great interest in integrating the DSS in Information Systems that already manage companies. With this objective, and in the scope of the bidding process, PRIMA ${ }^{1}$ (Alquier, et al., 2000) project was born. Usually, this process is developed with not too much automatization, without database support and its main resource is the group of persons that realize the bid. PRIMA final objective is a tool that allows to store, organize and reuse all the necessary information to build competitive bids.

Recently, there is an increasing interest on risk treatment in the organizations activities, (Grabowski et al., 2000). Theoretic appraisals have been developed, (Chapman and Ward, 1997) as attempts to carry out a formalization in this field. The need to manage uncertainty is inherent in most projects, which require risk management. The one-off, changeinducing nature of projects, need to organise a variety of resources under significant constraints and inherent uncertainty, should be taken into account to achieve important improvements in the project management and therefore, in the organizations. In this context,PRIMA has been conceived as a result of some customer needs that can be summarized as follows:

- The main Risk management standards or methods concern specialised or limited

\footnotetext{
${ }^{1}$ PRIMA is a research and technological development project partially supported by the Information Society Technologies (IST) Programme of the European Union's Fifth Framework programme.(http://www.esi2.us.es/prima/)
} 
definitions of risk. They don't follow and are not applied in the bid phase at all. They are used only for operational decisions during an on-going project.

- Companies are asking for additional functionality, innovative components, enlarged vision of risk, integration concepts, co-operative use and business enhanced value.

PRIMA project proposes a risk-based business approach established through:

- A "design to risk" method, which is a pro-active risk management approach focused and starting from the bidding process.

- A risk management corporate memory (RMCM) tool, which organises risk knowledge processing.

- A Decision support system (DSS) tool which assists and promotes the bidding method with a pricing decision support connected to risk knowledge processing. This paper will be focused on this point.

The DSS included in the tool aids in critical decision making and the building of bids in a systematically way. It supports:

- A mechanism for the bid manager to estimate and weight risks.

- Comparison of technical solutions for a bid by weighting their main parameters, including risks.

After an analysis about which techniques would be the most suitable for the design of the DSS, multicriteria algorithms have been adopted. The choice has been taken under consideration of the complexity of the decision making processes during the bidding process, featured by a large number of alternatives and multiple (and sometimes colliding) goals.

The paper is organized as follows. Next section contains an overview of the PRIMA project DSS, where the different phases will be described. In the third section, we will justify the algorithms and techniques used in the tool and some implementation details will be shown. Finally, we will present some conclusions.

\section{PRIMA DSS STRUCTURE}

A model for the bidding process has been designed in PRIMA project. The steps involved in this method are the following:

a) Preliminary Analysis of the document Request for Proposal (RFP) which is delivered by the client. The team project has to evaluate this document, with the objective of obtaining a quick bid or not bid decision.

b) If the team project decides to continue with the bid, the next step is building a technical solution. In PRIMA, this process is carried out according to a Top-Down approach, where the user can choose the detail level. c) When the technical solution is built, a selection among several suppliers and /or subcontractors for each element is realised. The target is to analyse how the different candidates could affect the final proposal, paying attention to parameters as cost, quality, time, viability,... There is a database that can provide information about this.

d) In PRIMA tool, a proposal is composed of the technical solution plus several properties as technical assistance, safety, terms of payment, financial package,... It is possible to produce several proposals for a same Request for Proposal. In this last step, a multicriteria assessment of each proposal is realized with the aim of choosing the final one.

According to this PRIMA model, there are three critical decision points in the bidding process:

- $\quad$ Bid/ No Bid Decision

- Make/Buy Decision

- Best Final Proposal

PRIMA DSS is based on three main points:

a) PRIMA tool performs a risk analysis in all the DSS phases. Causes, mitigation actions, impacts and evaluation algorithms are considered in the risks. The risk analysis previous to the decision, can cause modifications on the main parameters of the bid as costs, times,... Additional items as the presence or absence of a risk, or an overall evaluation of risks, are also taken into account during the decision process. These outcomes give very important information for the critical decisions.

b) PRIMA DSS makes possible the access to all the information related to the actual bid as well as similar historical bids, in a friendly way.

c) Assessments about the decision, both comparisons among different alternatives and "goodness" of a unique alternative.

\section{$2.1 \mathrm{Bid} /$ No bid Decision}

The objective is to determine in a quick way and with minimum resources whether the bid is interesting or not for the company.

In this first point, the tool provides information to aid in the preliminary bid/no bid decision. There is not a deep study of the bid, therefore, most of the available data have a low level of detail (usually fuzzy information). A preliminary decision has to be taken about proceeding with the development of the bid or dropping it out.

At the beginning of the bidding process, the available information is:

- The Request for Proposal

- A possible preliminary technical solution in a very low detail level 
- Previous experience about similar bids from the team project.

The information provided by PRIMA DSS in this point is:

- Historical data about client and previous similar bids.

- RFP Competitors

- Client Requirements.

- Company Requirements.

- Customizable Query about proposals and RFP.

- Qualitative appraisal on the RFP. This evaluation is carried out according to criteria and qualitative values, due to the low level of detail of the available information.

- Comparisons of preliminary proposals according to criteria selected by the user. The tool uses an Analytic Hierarchy Process (AHP) multicriteria algorithm. The nature of the used information is mainly qualitative but also quantitative. Scaling is a main issue in this assessment, as explained in next sections.

\subsection{Make/Buy Decision}

Technical solutions are built in PRIMA using decomposition techniques implemented on a tree structure. The root node is the final product requested by the client in the RFP. Every node represents a product or sub-product and the children of a node are its different components. The user can choose the level of detail adding or not more branches (tree depth).

The database contains information about external organizations that can supply or develop the products. Each node (product) of the tree may have associated suppliers and/or subcontractors representing the external company that respectively, could provide or develop the product. Prices and times provided by the selected organizations, are criteria to take into account in order to make posterior appraisals.

The objective of this point is to realize an assessment on the tree with all the possibilities of each link product-supplier/subcontractor. Examples of criteria are price, due date, risks indicators (exposure or impact), costs, ... PRIMA DSS shows as result a graphic with the several technical solutions assessment. Hence, user can decide what supplier/subcontractor is the best. Multicriteria decision algorithms are used in this point too.

\subsection{Final Decision of Best Proposal}

At this point suppliers and /or subcontractors have already been chosen for each node of the technical solution. The objective of the DSS in this last point is the selection of the best proposal among all the candidates. Each company should have their own criteria to realise the repetitive operations more quickly. PRIMA tool offers interfaces and procedures to store and recover this information in an easy way.

The most important outcome of this phase is the final evaluation of all the proposals, where qualitative and quantitative information can be mixed. It is necessary to highlight the need of establishing an absolute scale when quantitative data are treated. In PRIMA DSS the quantitative scale is determined by the user. The user can modify the scale when it was necessary. The existence of absolute scales assures the consistency in the results.

\section{IMPLEMENTATION}

The tool has been developed on a database relational schema and the programming language is Visual Basic. Multicriteria techniques have been used in the implementation, particularly, the AHP algorithm (Saaty and Alexande, 1989). Some modifications have been done to this algorithm.

Next, a description of the implemented multicriteria algorithm is presented. After that, some of the PRIMA tool screens will be shown in the same order as they were described in section 2 .

\subsection{Multicriteria Decision Analysis}

There are a number of fundamental problems when there are multiple objectives. For instance, consider the case where there are a number of decision makers, each with a preference ordering over a number of alternatives. Our goal is to choose the "fair" alternative that aggregates the preferences of the decision makers. This is an example of multiple criteria decision making (each decision makers represents one criteria), and we need to balance those objectives in a fair way.

Multiple Criteria Decision Analysis (also known under variety of names such as Multicriteria Decision Analysis, MultiAttribute Utility Theory, Multiple Attribute Decision Making and Multi Objective Decision Making) aims to help decision makers understand the problem situation and hence make 'better' decisions. Additionally, in the present economic and legal scope it is often necessary to justify the decisions. For example, the selection of employees is a decision situation, which requires the balancing, and trade off between a number of different criteria such as experience, the ability to 'fit in', capability, etc. However, the decision maker may be asked to justify their decision with regards to equal opportunities and justify that fairness prevails.

Analytic Hierarchy Process (AHP) There are a high number of different methods for decision making with multiple criteria (Kepner and Tregoe, 1983). AHP is one of the most popular techniques, which uses very simple calculations to try to put numerical 
values on criteria (decision criteria) and alternatives (candidates).

AHP Model was designed by Thomas L. Saaty (Saaty, 1989) as a decision making aid. It supports the choice-phase in decision-making process. It is suitable for complex decisions that involve the comparison of decision elements, which are difficult to quantify.

AHP can be used for the prioritisation of requirement. It compares the elements in a set of requirements pair to determine the degree of the importance of each requirement to the customer. It facilitates analytic thinking and it is a useful model for solving problems quantitatively.

When there is no enough time or resources to implement all requirements, AHP can be used as one of the prioritizing requirements methods to find the most critical requirements and implement them first. When there are conflicting in different stakeholders requirements, it can be used to identify conflicting. It can also help the planing of successive releases of products. The weakness of this technique is that prioritizing large set of requirement can be very tedious and time consuming.

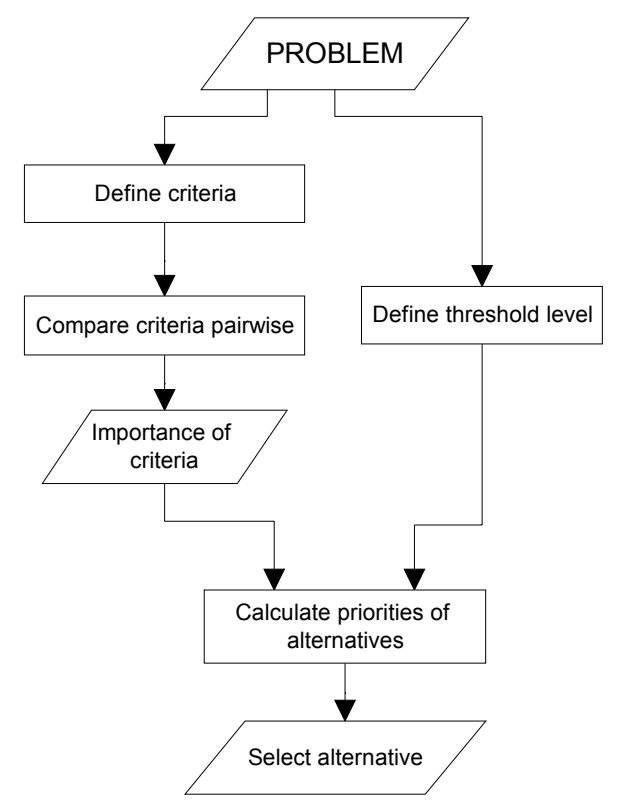

Fig. 1. PRIMA DSS Evaluation Algorithm phases.

PRIMA DSS evaluation algorithm (PDEA). The AHP algorithm has been adopted in PRIMA DSS to perform the candidate's evaluation. The steps of PDEA are illustrated in figure 1.

First, criteria have to be chosen by the user among the possibilities that the tool offers (see figure 2). Then, the weights associated to criteria can be introduced manually, when the user knows which are the specific weights that will be taken in the evaluation, or according to AHP method. The manual method is very useful when RFP includes the criteria to take the decision. Hence, criteria and weights are known. With the AHP algorithm, the user has to introduce values for the comparison between pairs of criteria. Criteria are the labels of both rows and columns (see table 1). The table has to be fulfilled by rows, where each item of the rows should be compared with each item of the columns.

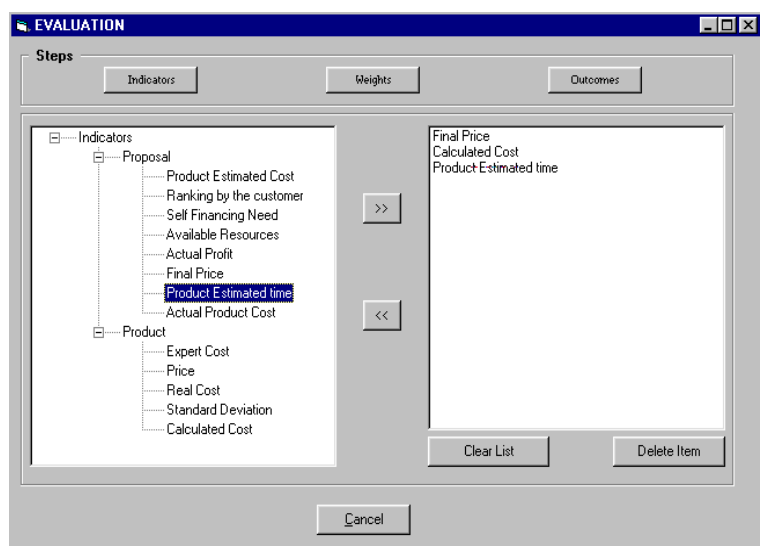

Fig. 2. Criteria selection screen.

The user determines whether the criteria associated with the row is more important than the one representing the column and if therefore, how much more important. In this paper, it has been adopted the scaling method defined by Saaty. If the column is more important than the row, inverse of the above values is used. The diagonal of the table where each entry is compared to itself will be all ones. The values of the table below the diagonal will be the inverse of the value above the diagonal (see table 1 and 2).

Table 1 AHP Table with criteria.

\begin{tabular}{|c|c|c|c|}
\hline & FP & $\mathbf{C C}$ & PT \\
\hline$\overline{\text { Final Price (FP) }}$ & 1 & 7 & 8 \\
\hline Calculated Cost (CC) & $1 / 7$ & 1 & 5 \\
\hline $\begin{array}{l}\text { Product Estimated Time } \\
\text { (PT) }\end{array}$ & $1 / 8$ & $1 / 5$ & 1 \\
\hline Totals & 1.27 & 8.2 & 14 \\
\hline
\end{tabular}

Define threshold level is related to the maximum or minimum values of a criteria than an alternative must to have to be considered as acceptable. If an alternative is outside of those limits in one criterion, it is rejected.

Table 2 Weights calculation

\begin{tabular}{|c|c|c|c|c|c|}
\hline & \multicolumn{3}{|c|}{ Normalized Columns } & \multirow{2}{*}{$\begin{array}{l}\text { Row } \\
\text { Sum }\end{array}$} & \multirow{2}{*}{$\%$} \\
\hline & FP & $\mathrm{CC}$ & PT & & \\
\hline FP & 0.79 & 0.85 & 0.57 & 2.21 & 73.67 \\
\hline CC & 0.11 & 0.12 & 0.36 & 0.59 & 19.67 \\
\hline PT & 0.1 & 0.03 & 0.07 & 0.2 & 6.66 \\
\hline otal & 1 & 1 & 1 & 3 & 100 \\
\hline
\end{tabular}


Multiple techniques can be used to rank the alternatives (Larichev, 2001). Actually, we are working with the following algorithm that values each one of the $\mathrm{j}$ candidates using the expression:

$$
P_{j}=\sum_{i=1}^{n} W_{i} * V_{i j,} \quad \forall j, \operatorname{tmin}_{i} \leq V_{i j} \leq \operatorname{tmax}_{i}
$$

where,

$P_{j}$, is the value for the $\mathrm{j}^{\text {th }}$ candidate

n, number of criteria

$W_{i}$, weight of $\mathrm{i}^{\text {th }}$ criteria

$V_{i j}$, is the normalized value of $\mathrm{j}^{\text {th }}$ candidate according to $i^{\text {th }}$ criteria

$\operatorname{tmin}_{j}$ and $\operatorname{tmax}_{j}$ are the threshold acceptance limits for the $i^{\text {th }}$ criteria

The best proposal will be that reaches the highest value.

\subsection{First Decision:Bid/No Bid Decision}

Figure 3 displays the main screen in the step $\mathrm{Bid} /$ no Bid decision. Several data as dates, budgets are illustrated in the screen. Figure 4 shows the outcomes of the proposal assessment according to the selected criteria and weights.

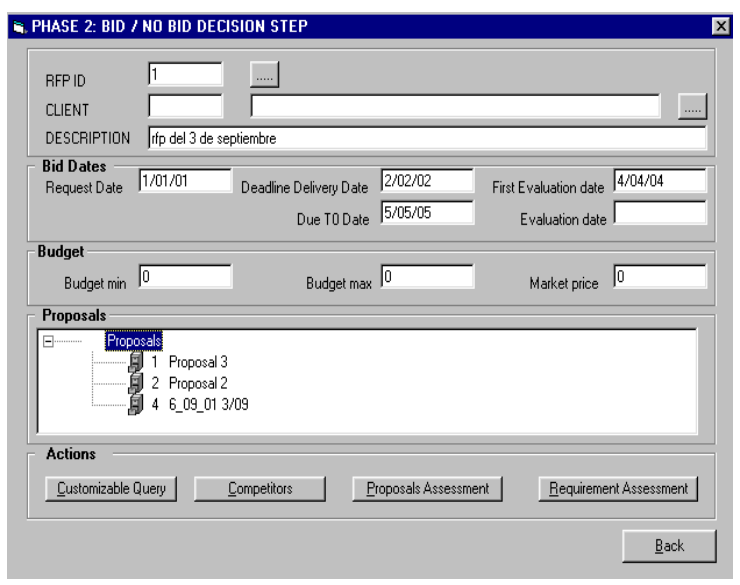

Fig. 3. Main screen of Bid/No Bid Decision

Note that actions as customizable queries, view competitors information and requirements assessment are possible in this phase. They can give rise to decisions with a higher consistency. Customizable queries let user the access to relevant information. They are implemented under an interface that allows working with the information in an easy way.

Requisites about our company, organizations and Request for Proposals are involved in the requirement assessment. Due to the variable nature of their values, it is important to have information about the status of these variables. At the assessment stage, all of them are evaluated depending on their optimal and real values.
All these functions add flexibility and adaptability to the tool.

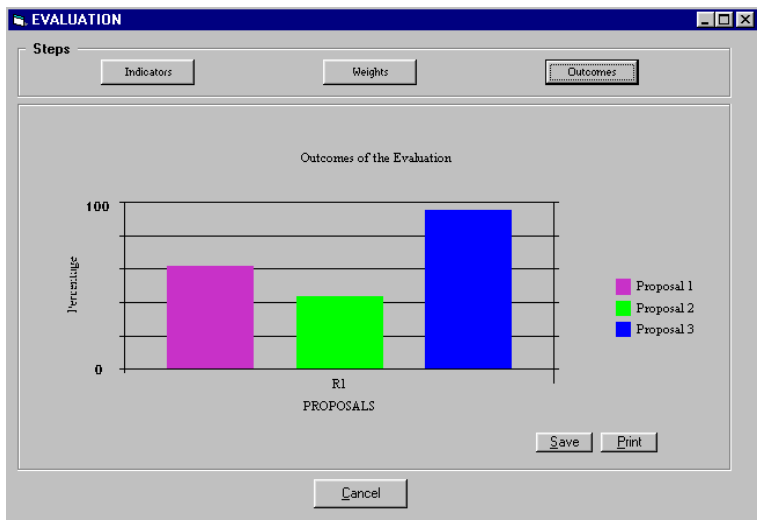

Fig. 4.Outcomes of proposal assessment in bid/no bid decision phase.

\subsection{Second Decision: Make/Buy Decision}

In the second phase, the objective is the selection of specific suppliers and/or subcontractors for each product. Previously, the user has selected the candidates for every one of them (with aid of the tool) and their links have been evaluated. Figure 5 depicts how the candidates and products are decomposed graphically. Hence, the objectives of this phase are:

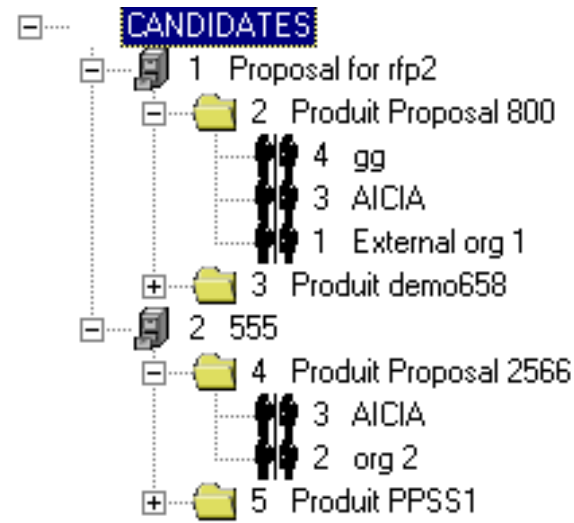

Fig. 5. Decomposition proposal-product-external organizations.

- Facilitate information to the user as client constraints (note that there is stored information about the constraints of each external organization), our company constraints...

- Realize customizable queries about subcontractors, RFP, proposals, products, historical bids, $\ldots$ in a friendly interface

- After the selection of criteria and values for the weight calculation, the tool will show an assessment about the goodness of each combination between products and suppliers and/or subcontractors. Thus, the user will be able 
of taking a decision about what suppliers/subcontractors are the best ones.

\subsection{Third Decision: Best Final decision choice}

The provided information in this phase is used for the last decision in the bidding process: What is the better option among all the proposals? This question is solved in this phase.

In this step it is possible to select criteria associated to products. Hence, an appraisal about proposals and products is possible at the same time.

Another function is the evaluation of candidates according to criteria and weights provided by the client. In the RFP the client usually exposes how all the received proposals will be evaluated. With this information, the user can realise tests with its proposals and as far as possible, on known data about the competence.

\section{CONCLUSIONS}

This work has been developed in PRIMA project scope. Several studies have been developed under industrial partners involved in the project. The need of including a decision tool to build the bids in their information systems, was an outcome of these studies. The repetitive nature of this action and the absence of stored electronic data (real or historical), have been decisive factors to undertake this work.

Some improvements that the use of the tool provides are:

- Fast decisions in the preliminary study to decide if allowing or not with the bid. Thus, a decrease for proposal preparation time is reached due to the early phase in which, no bid decision can be detected.

- Profitability increase thanks to a competitive work on each bid.

- Systematic exploitation of recurrent bids outcomes, previously realized. This function will have effects on the proposal preparation time and the fitting level.

- Decrease of biding prices (depending on the more or less recurrent bid type).

- Increase of turnover.

These innovative characteristics will give PRIMA tool a wide use and more numerous and varied users.

PRIMA tool has enough flexibility to manage the continuo challenges that organizations have to overcome.

Finally, it is important to enhance the necessity of constant database updates to which the Decision Support System accesses. The absence of this requirement will produce no viable solutions and outcomes with little quality.

\section{ACKNOWLEDGMENTS}

The authors gratefully acknowledge Fernando Dorado and Marta Fernandez for their useful suggestions and for improving the presentation of the paper.

\section{REFERENCES}

Alquier, A.M., E. Cagno, F. Caron and M.A. Ridao. Analysis of external and internal risks in project early phase. PMI Research Conference 2000.

Chapman, C. And S. Ward. (1997) Project Risk Management . Processes, Techniques and Insights. John Wiley \&Sons.

Davenport T. And L. Prusak (1998). Working Knowledge. How Organizations manage what they know. Harvard Business School Press

Druzdzel, M., and R. Flynn .(1999). Decision Support Systems. Encyclopedia of Library and Information Science. (1999). Alle Kent (Ed.)Dekker Inc.

Grabowski, M. , J. Merrick, J. Harrald, T. Mazzuchi and J. Van Dorp. (2000). Risk Modeling in Distributed, Large-Scale Systems. IEEE Transactions on Systems, Man, and Cybernetics, 30, 651-660

Gray, P., (1994)Decision Support and Executive Information Systems .. Prentice Hall

Keen, P., and M. Morton (1978). Decision Support Systems: an organizational perspective.AdisonWesley.

Kepner C. And B. Tregoe (1983). The new rational manager. Mc Graw-Hill.

Larichev, O (2001). Ranking multicriteria alternatives_ The method ZAPROS III. European Journal of Operational Research 131, 550-558

Saaty T. And J.M. Alexande. (1989). Conflict resolution: the Analytic Hierarchy Process. Praeger

Seydel J, and D.L. Olson (2001). Multicriteria Support for Construction Bidding, Mathematical and Computer Modelling 34, 677-702.

Simon, H., The New science of Management Decision. (1960)Harper \&Row

Sprague, R. and B. McNurlin. (1993). Information Systems Management in practice. Prentice Hall

Thierauf, R.(1982).Decision Support Systems for Effective Planning and Control.Prentice Hall

Turbam, E., (1988). Decision Support and Expert Systems. Maxwell MacMillan 